\title{
A New Species of Tarantula Spider in the Genus Lyrognathus Pocock 1895 (Araneae, Theraphosidae) from Sumatra
}

\author{
Steven C. Nunn ${ }^{1}$ and Rick C. West ${ }^{2}$ \\ ${ }^{1} 43$ Range Road, Sarina, QLD 4737, Australia \\ ${ }^{2} 6365$ Willowpark Way, Sooke, British Columbia, Canada V9Z 1L9 \\ Correspondence should be addressed to Steven C. Nunn; cnu84149@bigpond.net.au
}

Received 30 January 2013; Accepted 15 March 2013

Academic Editors: B. Crother, S. Fattorini, L. Kaczmarek, and C.-F. Weng

Copyright (C) 2013 S. C. Nunn and R. C. West. This is an open access article distributed under the Creative Commons Attribution License, which permits unrestricted use, distribution, and reproduction in any medium, provided the original work is properly cited.

A new species is described in the tarantula genus Lyrognathus Pocock 1895, being the first record of this taxon from Sumatra, Indonesia. Lyrognathus giannisposatoi sp. nov. is also unique in its habitat selection, being the first confirmed lowland species from this genus. A new key to Lyrognathus species is provided, and a biogeography of the group is briefly discussed.

\section{Introduction}

Lyrognathus Pocock 1895 belongs to the tarantula subfamily Selenocosmiinae Simon 1889 and was first described in northeastern India (L. crotalus Pocock [1], L. saltator Pocock [2]), then a century later in West Malaysia (L. robustus Smith [3], West [4]), and more recently on Borneo (L. achilles West and Nunn [5], L. fuscus West and Nunn [5]) and Lombok islands (L. lessunda West and Nunn [5]). West and Nunn revised the genus [5] and in 2012 subjected Lyrognathus to cladistic analyses and also discussed biogeographical history of the group [6]. All previously described species have been recorded at higher elevations in montane habitat $[1,2,4,5,7]$ and are a relatively medium to small-sized group [5]. Lyrognathus giannisposatoi sp. nov. is the most robust member of the genus and is the first to be recorded from Sumatra. $L$. giannisposatoi sp. nov. is unique among Lyrognathus in its preference for lowland elevations (F. Schneider, pers. comm.). A new key to species and map of Lyrognathus are also included.

\section{Material and Methods}

Taxonomic description style follows Raven [8] and West and Nunn [5]. All measurements are given in millimeters $(\mathrm{mm})$ and were made to the nearest $0.01 \mathrm{~mm}$ with the aid of a squared eyepiece and digital dial callipers. Life images were taken with a Nikon CP8800 digital camera. Taxonomic images were taken by mounting a Nikon CP8800 digital camera to the phototube of a WILD Heerbrugg M8 stereozoom microscope (plus 1.6X objective lens) via the Scopetronix Maxview TM system, with external cold light illumination. Additional images of paratypes in the SMF were taken by Wirth with a Novex RZ Range trinocular microscope and a Nikon CP4500 digital camera, with external cold light illumination. The species diagnosis defines L. giannisposato sp. nov. from all others within the genus, not just its closest relatives. Leg and pedipalp measurements were taken from their dorsal aspect on the left side (unless appendages were lost or obviously regenerated) of all specimens, and coxae and trochantera were measured from their ventral aspect, on the same side. Eyes in sizes of largest to smallest (including distances taken at widest points in length/width, resp.). Claws are not included in the measurements of tarsi. Total body length measurements include chelicerae. Sternal sigilla measurements include labiosternal sigilla. Hair types are described (following [5]). Spermathecae were dissected from females and cleaned in concentrated lactic acid for 48 hours. Spermathecae of SMF type specimens were heated with concentrated lactic acid for about two to five minutes, until cleaned. The Leg formula is given in order of size from largest to smallest in both length and width. Leg relation factor [RF ] 


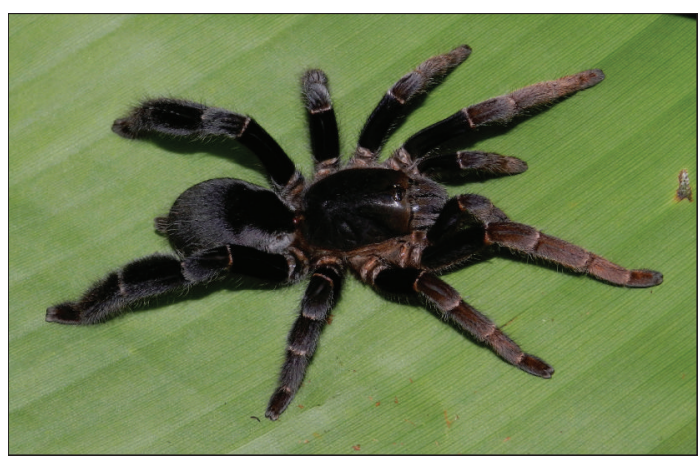

(1)

FIGURE 1: Lyrognathus giannisposatoi sp. nov. Holotype female, QM S95160, in life, from Mesuji, Lampung Province, Sumatra, Indonesia. Photo: West.

(following [9]) is calculated by multiplying the length of leg I by 100 , then dividing by the length of leg IV. $100=$ equal sized leg I-IV, above 100 on a sliding scale representing a longer leg I, below 100 on a sliding scale representing a longer leg IV. Trichobothrial terminology follows Raven [8]. Scopula extents are given as distal extents; that is, $2 / 3$ means for distal two-thirds and refers to the ventral extent. DIVA-GIS Version 5.4.0.1 was utilized for geographic plotting. New type material will be housed at the QM (holotype female, 1 paratype female, and 1 paratype male), the SMF (4 paratype females and 1 paratype male), and the NHM (2 paratype females). Because mature females display more informative characters in Lyrognathus than males do, a female was selected as the holotype. Most types from this genus are female and some males are not known; therefore, the dichotomous key applies only to females.

Materials from the following institutions were cited, examined or images of type material were supplied to the authors: Natural History Museum (NHM), London; Queensland Museum (QM), Brisbane; Raffles Museum of Biodiversity Research (RMBR), Singapore; Senckenberg Museum, Frankfurt am Main (SMF); Zoological Museum University of Copenhagen (ZMUC), Copenhagen; Zoological Survey of India (ZSI), Calcutta.

\subsection{Material}

2.1.1. Type Material. Lyrognathus achilles West and Nunn 2010, holotype female, S88049; paratype male S88050; 2 paratype females S88047 and S88048, Ganung Nibung $\left[2^{\circ} 07^{\prime} \mathrm{S}, 112^{\circ} 00^{\prime} \mathrm{E}\right]$, Kotawaringin Barat, Borneo, Indonesia, col. Yanto, 2 Apr. 2009, QM-examined.

Lyrognathus crotalus Pocock 1895, holotype female, 1854.16, Assam State, northeastern India, NHM-images and illustrations (Raven, Smith, pers. comm.).

Lyrognathus fuscus West and Nunn 2010, holotype female, 3 paratype females S88054, S88051, S88052 and S88053, respectively, Simpang Kubur $\left[2^{\circ} 29^{\prime} \mathrm{S}, 111^{\circ} 25^{\prime} \mathrm{E}\right]$, Kotawaringin, Kotawaringin Barat, Borneo, Indonesia, col. Yanto, 2 Apr. 2009, QM-examined.

Lyrognathus lessunda West and Nunn 2010, holotype female, 1 paratype female, 3 paratype males, S74067, S74066,
S74070, S74068 and S74069, respectively, Lombok Island $\left[8^{\circ} 08^{\prime} \mathrm{S}, 117^{\circ} 24^{\prime} \mathrm{E}\right]$, Lesser Sunda Islands, Indonesia, col. Sutrino, 15 Aug. 2002, QM-examined.

Lyrognathus liewi (jun. syn. of L. robustus) West 1991, holotype female, 2 paratype females, S15460, S15461 and S15462, respectively, 24 mile road marker, Cameron Highlands $\left[4^{\circ} 41^{\prime} \mathrm{N}, 101^{\circ} 52^{\prime} \mathrm{E}\right.$ ], Pahang, West Malaysia, col. Liew, Oct.-Nov. 1986, QM-images (Raven, pers. comm.)-examined.

Lyrognathus pugnax (jun. syn. of L. crotalus) Pocock 1900, holotype female, 1895.1.28.1, Shillong [ $25^{\circ} 34^{\prime} \mathrm{N}, 91^{\circ} 53^{\prime} \mathrm{E}$ ], Meghalaya State, northeastern India, NHM-images, illustrations (Wirth, Smith, pers. comm.).

Lyrognathus robustus Smith 1988, holotype female, 1988.2.6, Cameron Highlands, Malaysia, (unknown collector and date), NHM - images (Raven, pers. comm.) - examined.

Lyrognathus saltator Pocock 1900, holotype female, 1897.6.24.24, North Khasi Hills [ $\left.25^{\circ} 34^{\prime} \mathrm{N}, 91^{\circ} 37^{\prime} \mathrm{E}\right]$, Meghalaya State, Northeast India, NHM-images, illustrations (Wirth, Smith, pers. comm.).

2.1.2. Other Material. Lyrognathus crotalus Pocock 1895, topotypic female, 09.10.7.36, North Khasi Hills, Meghalaya State, northeastern India, NHM-images and illustrations (Wirth, Smith, pers. comm.); male, 00000641, North Khasi Hills, Meghalaya State, northeastern India, ZMUCillustrations (Smith, pers. comm.); male, 1853.54-11, Shillong, Meghalaya State, northeastern India, ZSI-illustrations (Smith, pers. comm.); 1 female, 1 male S88362, S88361, Darugiri $\left(25^{\circ} 37^{\prime} \mathrm{N}, 90^{\circ} 45^{\prime} \mathrm{E}\right)$, Meghalaya State, northeastern India, QM-examined.

Lyrognathus robustus Smith 1988, 3 females, 2 males, S15641, S74339, S74341, S74342 and S15641, S74340, respectively, Cameron Highlands, Pahang, West Malaysia, QMexamined; 1 male, S88073, Maxwell Hill (= Bukit Larut, $\left.4^{\circ} 52^{\prime} \mathrm{N}, 100^{\circ} 48^{\prime} \mathrm{E}\right)$, Perak, West Malaysia, QM-examined; 2 females, ZRC ARA.747, Taiping $\left(4^{\circ} 51^{\prime} \mathrm{N}, 100^{\circ} 48^{\prime} \mathrm{E}\right)$, Perak, West Malaysia, col. Abraham, 1 Nov. 1925, RMBR_images (D. Court, pers. comm.)-examined.

\subsection{Taxonomy}

2.2.1. Lyrognathus Pocock 1895 (Figures 1-9(34)). Lyrognathus Pocock 1895: 170, 175, 1900: 187, 202; Simon 1903 [10]: 954, 956; Gravely, 1915a [11]: 415; 1915b [12]: 284; 1935 [13]: 83; Roewer, 1942 [14]: 6; Raven 1985 [15]: 38, 118; Smith 1986, 1987 [3, 16]: 121, 1988 [7]: 14; West 1991 [4]: 615; West and Nunn 2010: 1-43; West, Nunn and Hogg 2012 [6]: 13, 14, 32, 38; Platnick, 2013 [17].

Diagnosis. (following $[5,6])$ Lyrognathus differs from other Selenocosmiinae genera in having dense penicillate retrolateral setal brushes along tibiae and metatarsi IV (West and Nunn, Figures 3, 20, 54, 71, 98, and, herein, Figure 3(13)), very incrassate tibiae IV (West and Nunn, Figures 8, 21, 53, 71, 99, and, herein, Figures 1 and 3(13)) and having undivided metatarsi IV scopula in females (West and Nunn, Figures 19, 54,74 ), except L. robustus Smith 1988, which shows a possibly unique form of division of the metatarsi IV scopula by 


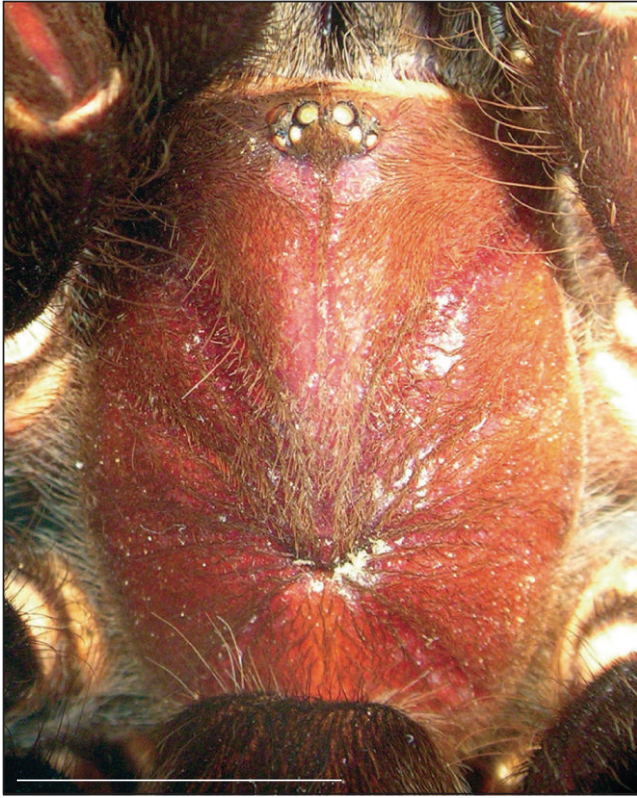

(2)

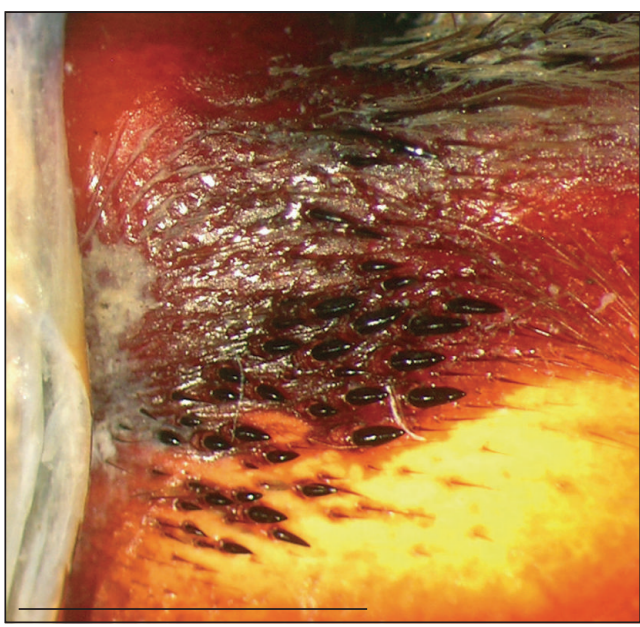

(5)

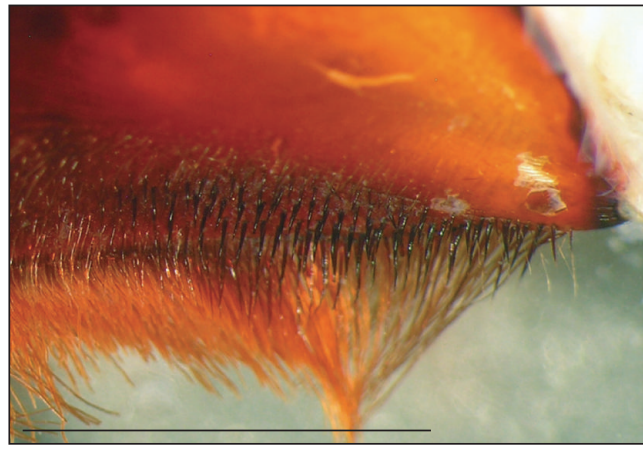

(7)

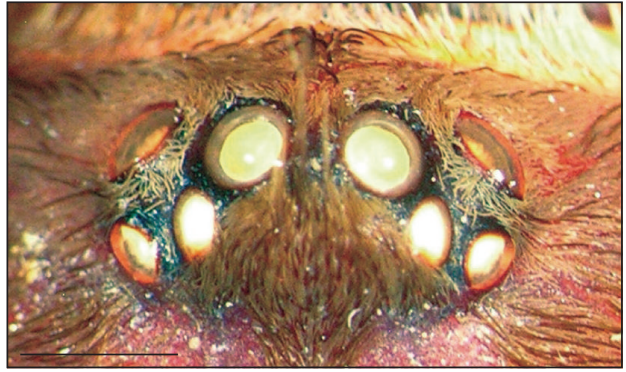

(3)

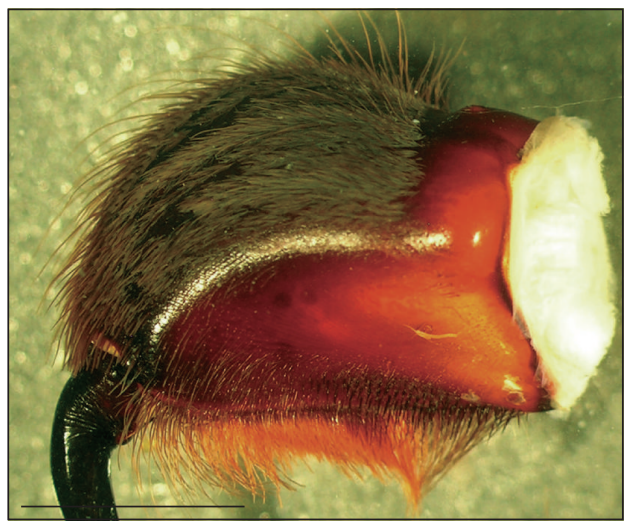

$(4)$

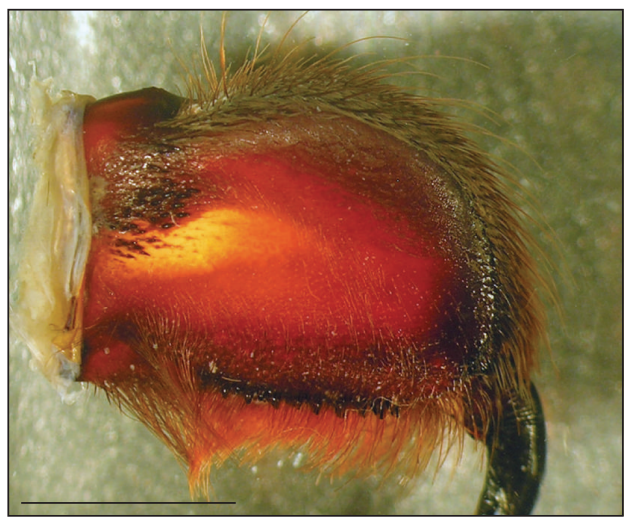

(6)

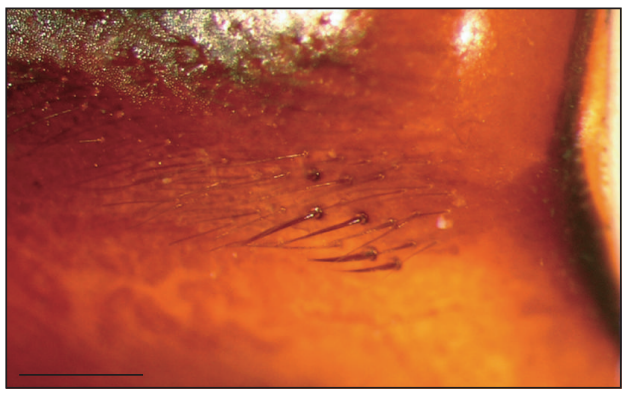

(8)

FIGURE 2: (2) Lyrognathus giannisposatoi sp. nov., holotype female, QM S95160, carapace, dorsal view. (3) Eyes, dorsal view: (4) paratype female, QM S95162, left chelicera, retrolateral view. (5) Intercheliceral pegs, prolateral view. (6) Left chelicerae, prolateral view. (7) Cheliceral strikers, retrolateral view. (8) Retrolateral basomedial cheliceral spines, retrolateral view. Scale bar = $10 \mathrm{~mm}$ for (2); $2 \mathrm{~mm}$ for (3), (5); $5 \mathrm{~mm}$ for (4), (5), and (6); $1 \mathrm{~mm}$ for (8). Photos: Nunn. 


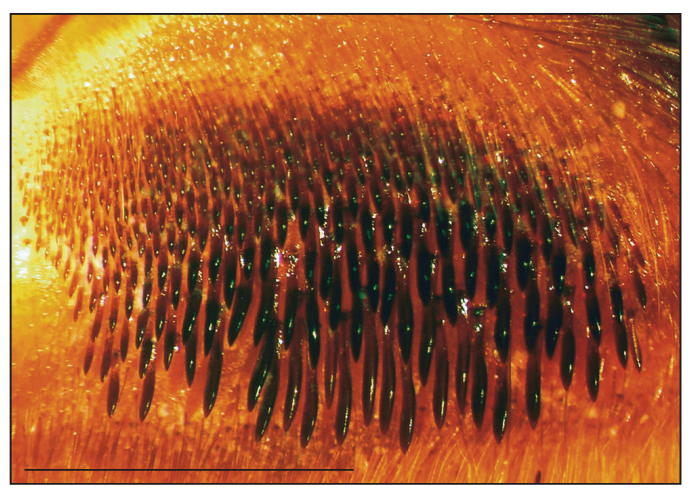

(9)

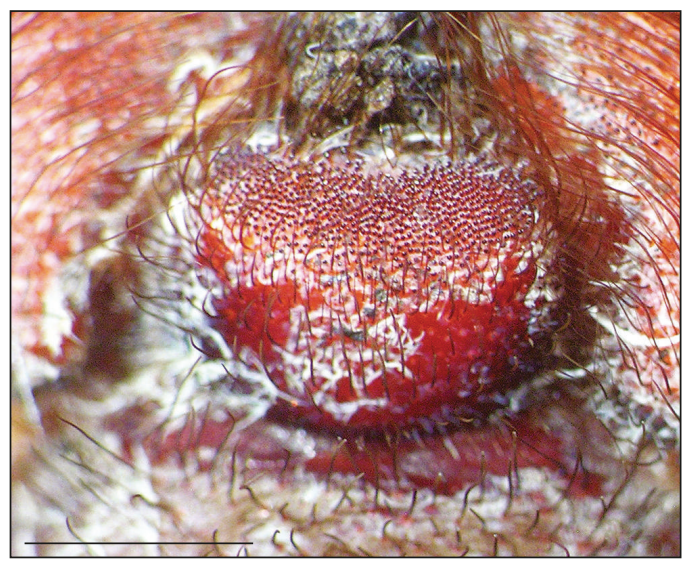

(11)

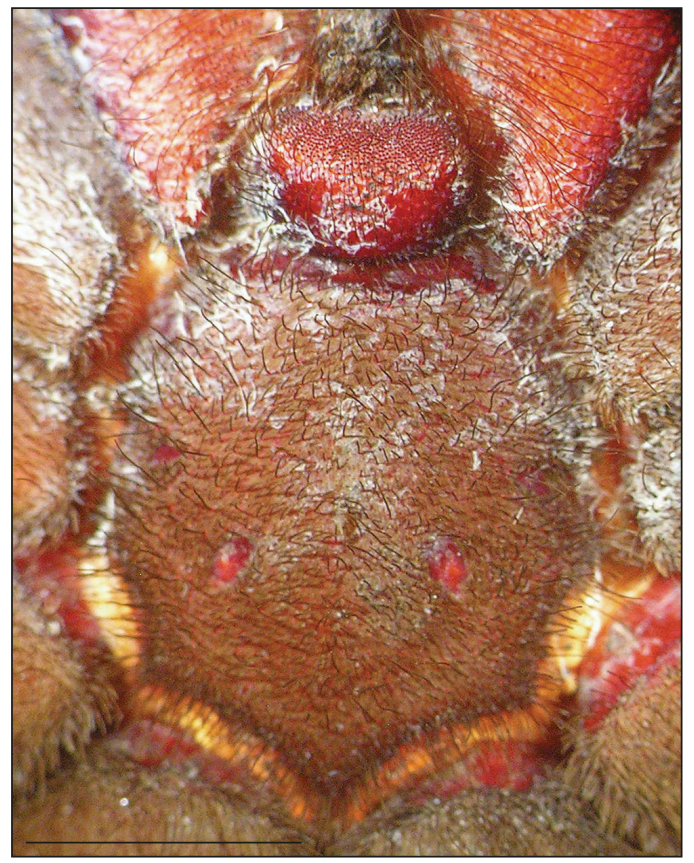

(12)

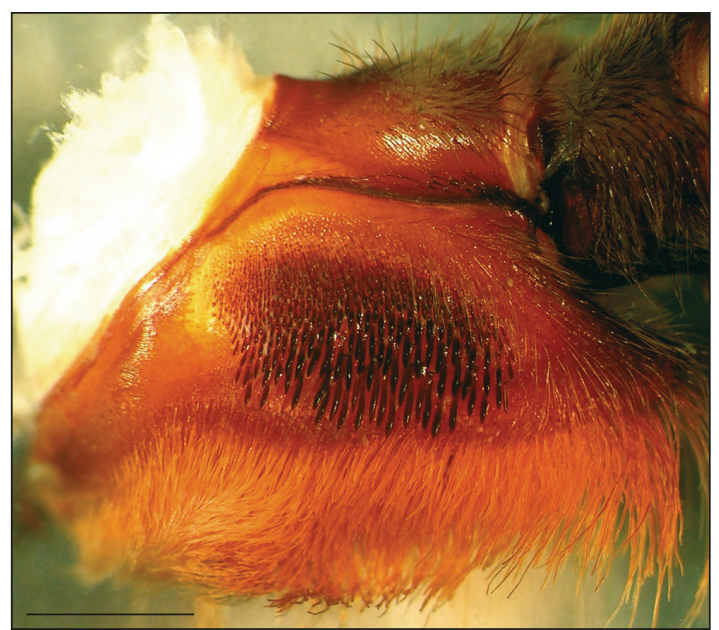

$(10)$

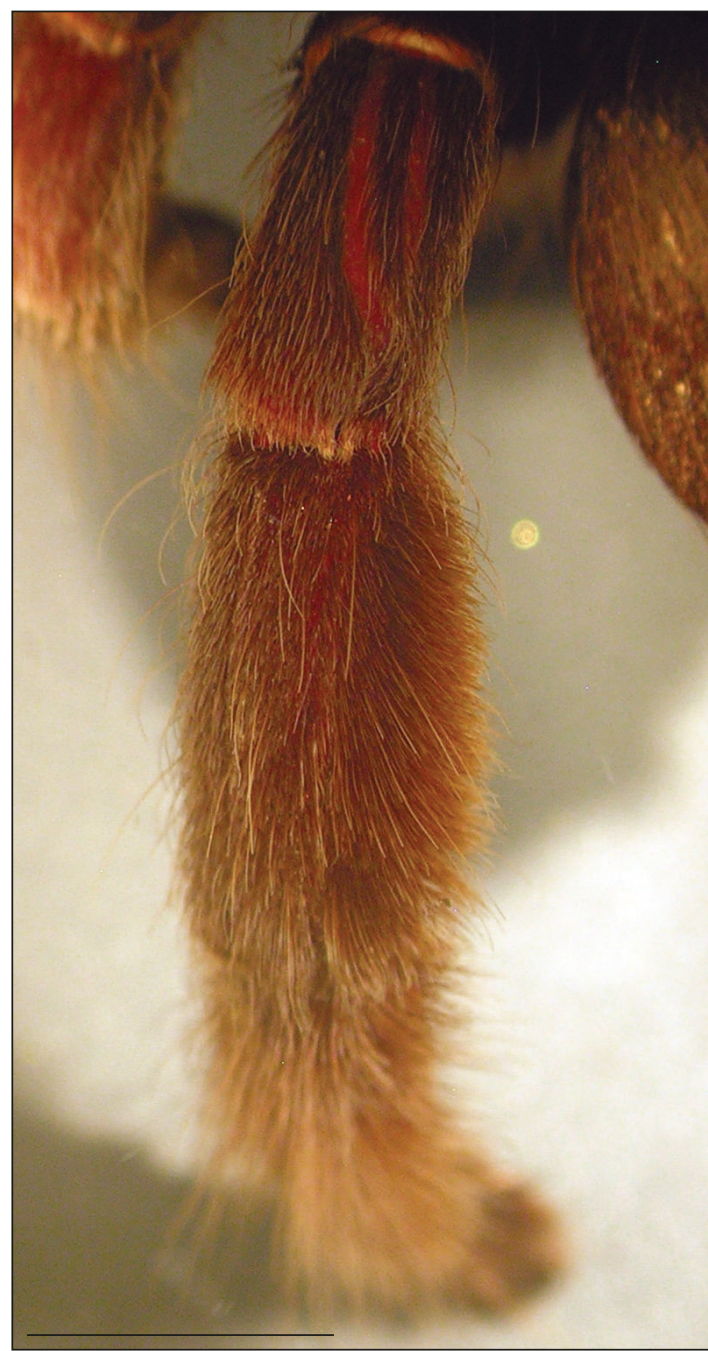

(13)

FIGURE 3: (9) Lyrognathus giannisposatoi sp. nov., paratype female, QM S95162, maxillary lyra, prolateral view. (10) Maxilla, prolateral view: (11) Holotype female, QM S95160, labium, ventral view. (12) Sternum, ventral view. (13) Left patella and tibia IV, dorsal view. Scale bar $=2 \mathrm{~mm}$ for (9), (10), and (11); $5 \mathrm{~mm}$ for (12), (13) Photos: Nunn. 


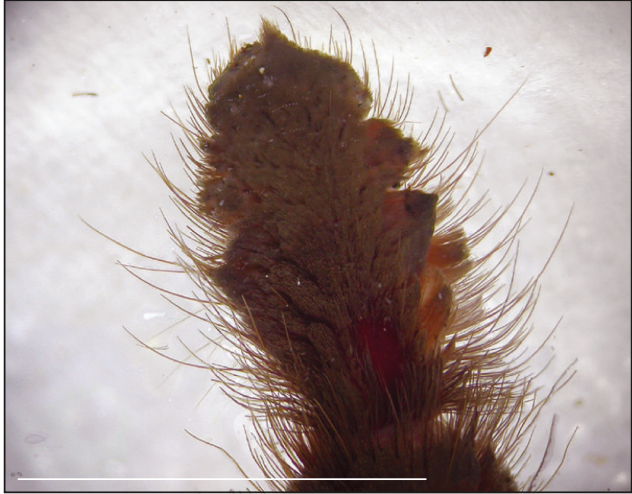

(14)

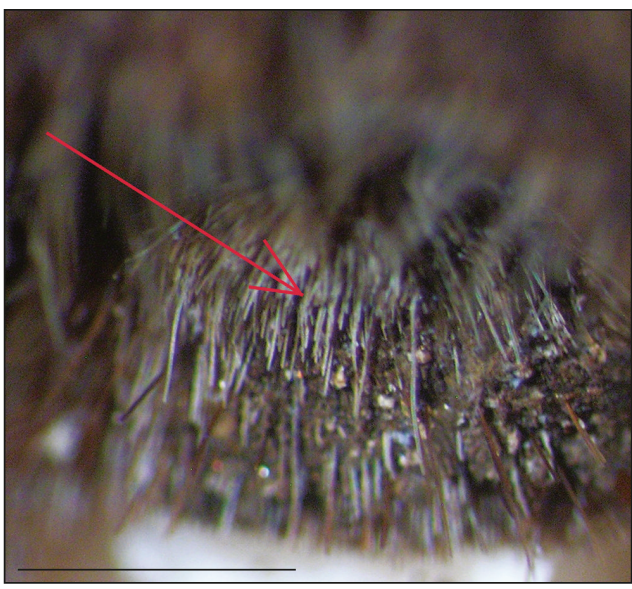

(16)

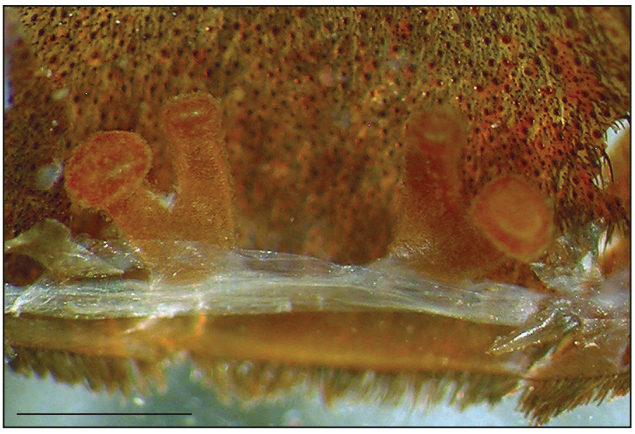

(17)

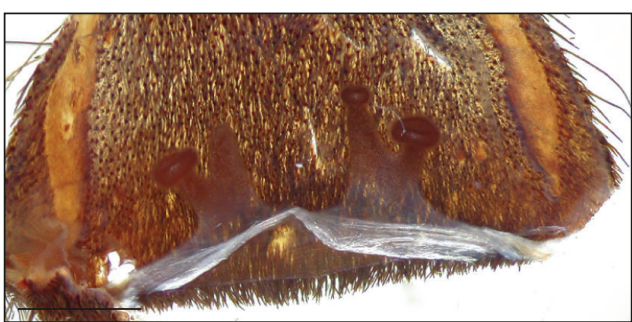

(19)

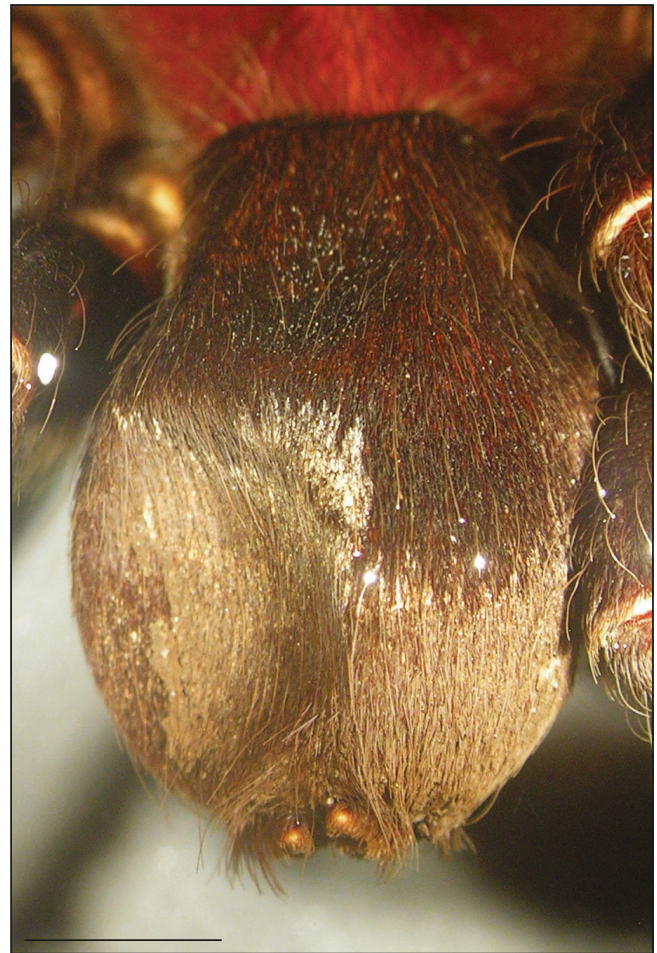

(15)

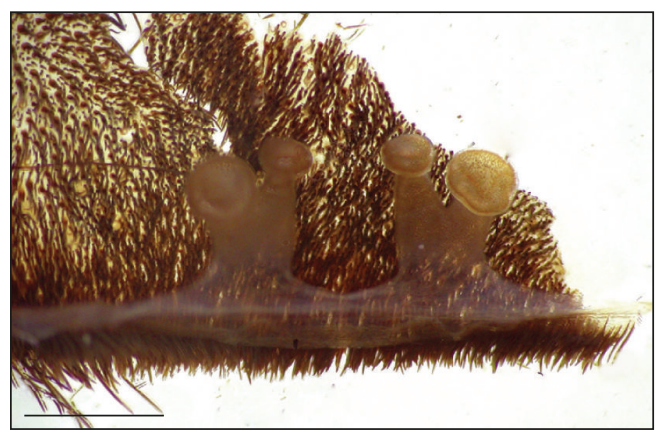

(18)

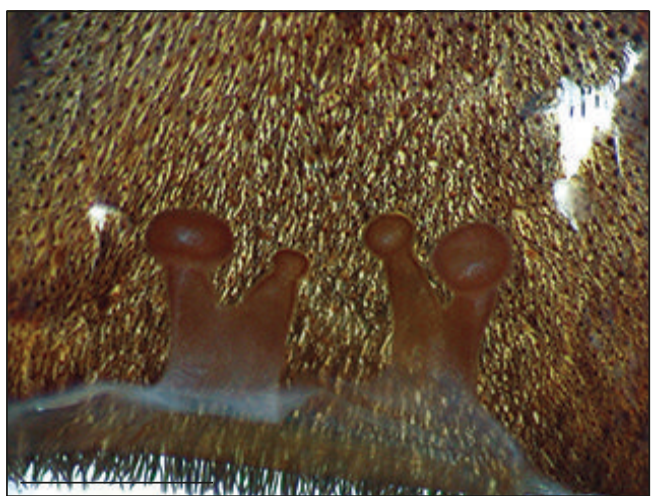

(20)

FIGURE 4: (14) Lyrognathus giannisposatoi sp. nov., paratype female, SMF, tarsus IV, ventral view. (15) Holotype female, QM S95160, abdomen, dorsal view. (16) Hair type 4 (A4), ventral view. (17) Spermatheca, dorsal view. (18)-(20) Paratype females, SMF 10/FS/2012, 3/FS/042012, 2/FS/042012, respectively, spermathecae, dorsal view. Scale bar $=5 \mathrm{~mm}$ for (10), (14), and (15); $1 \mathrm{~mm}$ for (16), (17)-(20). Photos: (15)-(17), Nunn; (14), (18)-(20), Wirth. 


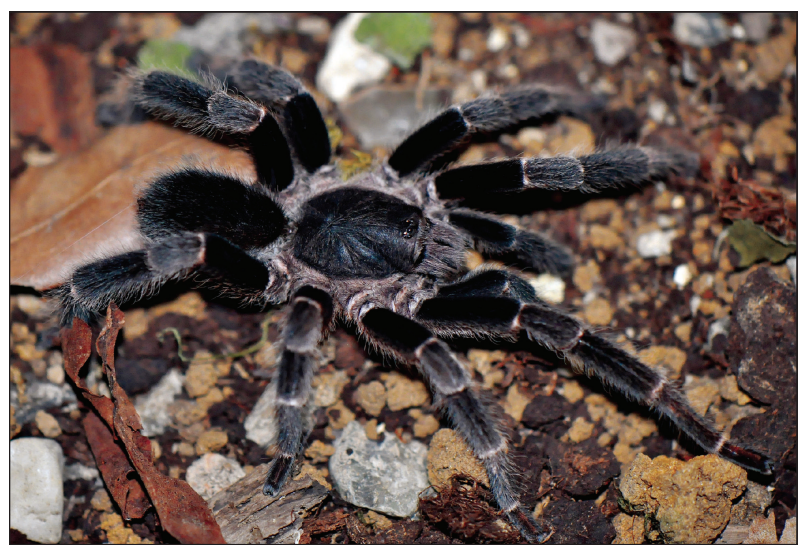

$(21)$

FIGURE 5: Lyrognathus giannisposatoi sp. nov., nontype male in life, from Mesuji, Lampung Province, Sumatra, Indonesia. Photo: Verdez.

extremely stout, spiniform setae (see: [5, Figure 98]). Lyrognathus further differs in that the male embolus is entirely lanceolate with a singular retrolateral keel extending ventrally and proximally (West and Nunn Figures 5, 40, 89, 90, and, herein, Figures 7(30) and 7(31)), except for L. robustus, which lacks the keel [5]. Within the tribe Selenososmiini Simon 1889, Lyrognathus differs from Selenocosmia Ausserer 1871 from Java and Sumatra and from Coremiocnemis Simon 1889 and Psednocnemis West et al. 2012 from Malaysia (males and females) in the above traits, in the large size of posterior sternal sigilla and that the clavate trichobothrial field on tarsi I-IV occur in distal 1/2 (in Malaysian, Javan and Sumatran species of Psednocnemis, Selenocosmia, and Coremiocnemis, clavates extend to distal $3 / 4$ of all tarsi) and general leg morphology besides that diagnosed above.

Type Species. Lyrognathus crotalus Pocock 1895, by original designation and monotypy.

Description. (following $[5,6]$ ) A selenocosmiine theraphosid genus with incrassate leg IV combined with penicillate retrolateral setal brushes on tibia IV in both sexes (except in male L. robustus), leg length formula IV, I, II, III (both sexes), leg width formula IV, III, I, II (females), almost circular ocular tubercle-higher posteriorly, with fovea of equal width, clypeus absent, retrolateral surface of coxae IV entirely hirsute (except in $L$. crotalus, L. saltator and $L$. robustus), >2 DV, 1DPV, 1DRV, 1DD metatarsal III/IV spine arrangement, no basofemoral spines, retrolateral basomedial spine cluster on chelicerae (present/absent), keeled/terete lanceolate embolus that emerges from tegulum anteriorly, with small basoventral projection present/absent, intercheliceral peg or spiniform setae, bilobular spermathecae with lateral lobes at $2 / 3$ to $3 / 4$ length of medials (most species) or unilobular spermathecal receptacles (L. crotalus Pocock [1]), spermathecae heavily sclerotized distally, grading to clear shafts proximally, metatarsi IV scopula divided (L. robustus) or undivided (all other species), metatarsi IV scopula in distal $1 / 3$ (L. robustus) or for full length (all other species), unarmed paired claws, third claw on leg IV present (L. robustus) or absent (all other species), and clavate trichobothria on distal $1 / 2$ of all tarsi, very long. No dorsal carapace thorns.

Species Included.

(i) Lyrognathus crotalus Pocock 1895

(ii) Lyrognathus achilles West and Nunn 2010

(iii) Lyrognathus fuscus West and Nunn 2010

(iv) Lyrognathus lessunda West and Nunn 2010

(v) Lyrognathus robustus Smith 1988

(vi) Lyrognathus saltator Pocock 1900

(vii) Lyrognathus giannisposatoi sp. nov.

Distribution. Northeastern India, West Malaysia, Sumatra, Borneo, and Lombok Island.

Identification Key for Adult Lyrognathus Females. (following [5], with amendment for couplet 4 and with inclusion of $L$. giannisposatoi sp. nov.).

(1) Scopula on metatarsi IV divided by band of strong spiniform setae [5, Figure 98] — L. robustus Smith 1988

Scopula on metatarsi IV undivided [5, Figure 19] -2 ,

(2) Basodorsal intercheliceral surface with strong spiniform setae [5, Figure 10] -3

Basodorsal intercheliceral surface with pegshaped thorns [5, Figure 28] -4 ,

(3) Metatarsi IV with 6 apical spines-L. saltator Pocock 1900

Metatarsi IV with 5 apical spines $-L$. crotalus Pocock 1895,

(4) Scopula on tarsi IV undivided [5, Figures 74 and 14] 6

Scopula on tarsi IV divided in apical half by one row of 5-6 setae [5, Figure 74]-5,

(5) Retrolateral tibiae IV brush uniform along entire surface [5, Figure 20] - L. achilles West and Nunn 2010

Retrolateral tibiae IV brush lacking proximally, increasing distally [5, Figure 53] - L. fuscus West and Nunn 2010,

(6) Largest intercheliceral pegs blunt tipped [5, Figure 78] - L. lessunda West and Nunn 2010

Largest intercheliceral pegs pointed, sharp tipped (Figure 5) - L. giannisposatoi sp. nov. 


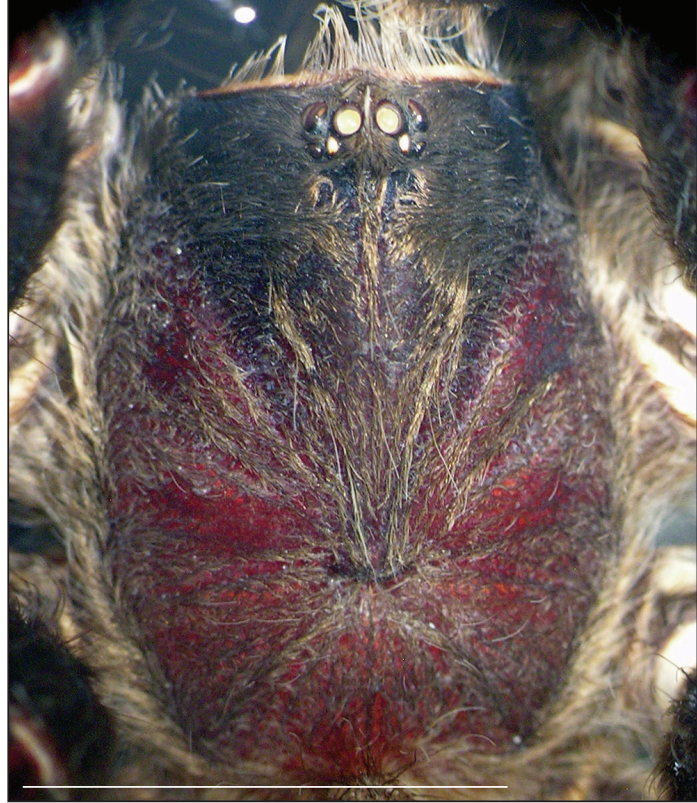

(22)

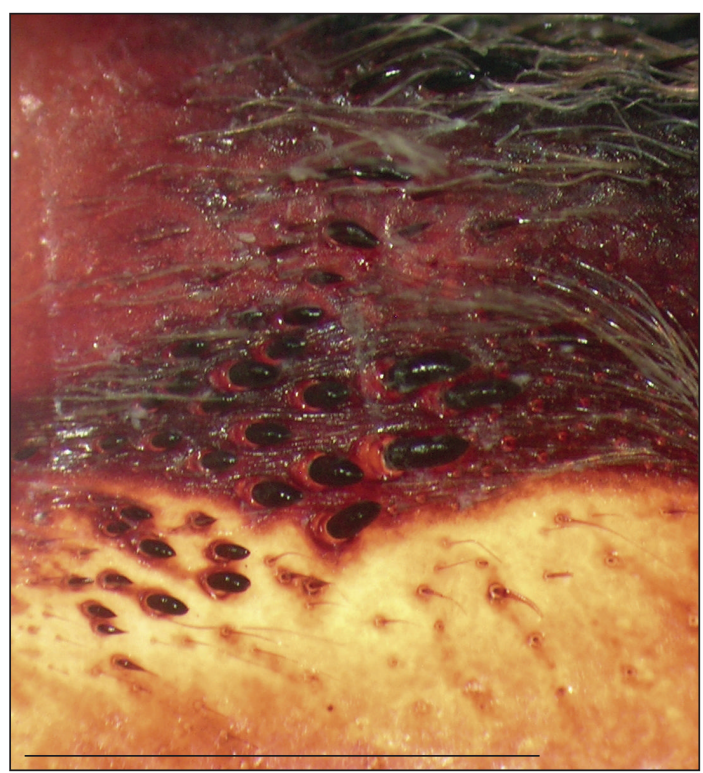

(25)

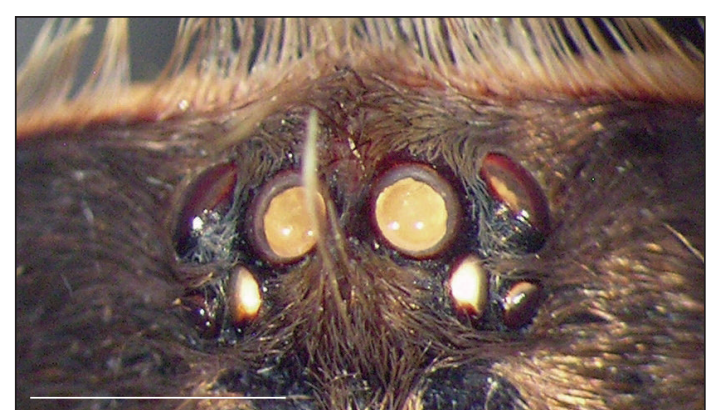

(23)

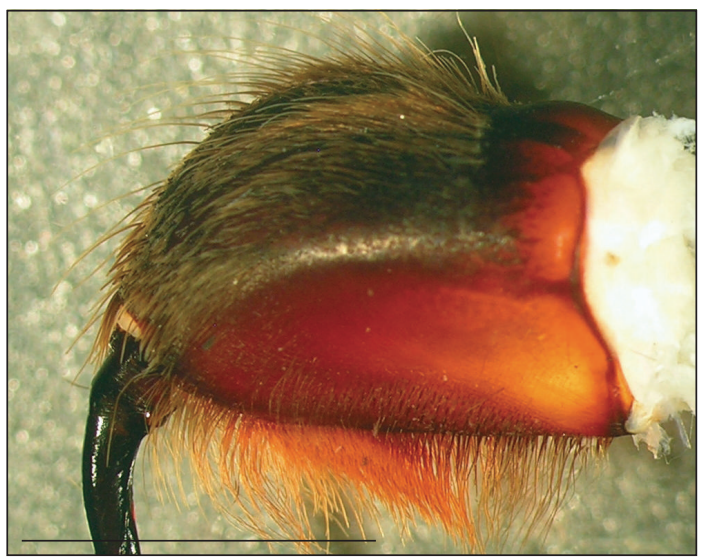

$(24)$

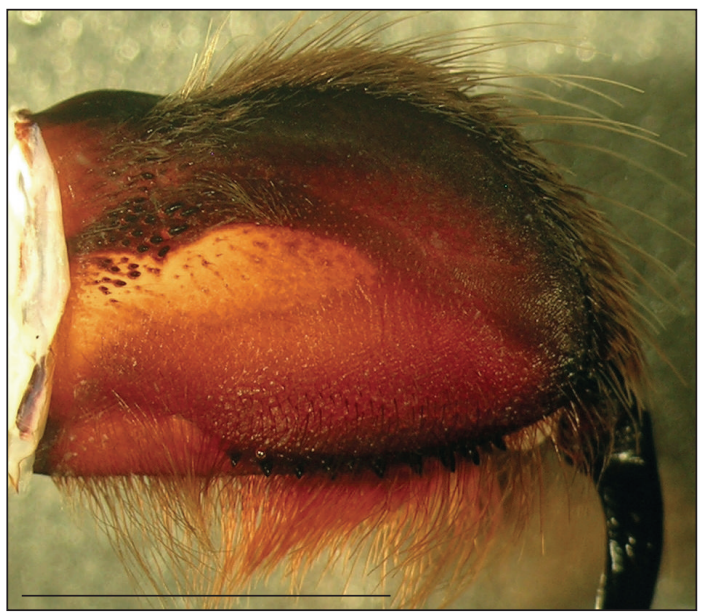

(26)

FiguRE 6: (22) Lyrognathus giannisposatoi sp. nov., paratype male, QM S95161, carapace, dorsal view. (23) Eyes, dorsal view. (24) Chelicera, retrolateral view. (25) Intercheliceral pegs, prolateral view. (26) Chelicera, prolateral view. Scale bar $=10 \mathrm{~mm}$ for (22); $2 \mathrm{~mm}$ for (23); $5 \mathrm{~mm}$ for (24), (26); and $2 \mathrm{~mm}$ for (25). Photos: Nunn.

Note. Wirth (pers. comm.) noted enough spermathecal variation within Lyrognathus giannisposatoi sp. nov.paratypes (Figures 4(18)-4(20)) to reconsider the stability of couplet 4 in West and Nunn [5], which is centered on variation of the medial bilobe distally. Additionally, West [4] illustrated spermathecal variation among three of his Lyrognathus liewi (now a jun. syn. of L. robustus) type series. As such, West and Nunn's [5] couplet 4 has been changed to avoid the above ambiguity for diagnosis.

\subsubsection{Lyrognathus giannisposatoi sp. nov. (Figures 1-7(31))}

Types. Holotype female QM S95160; 1 paratype male QM S95161; 1 paratype female QM S95162, Mesuji [ $\left.4^{\circ} 1^{\prime} \mathrm{S}, 105^{\circ} 31^{\prime} \mathrm{E}\right]$, Lampung Province (North), Sumatra, Indonesia, col. Schneider, April 2012, QM-examined; 4 paratype females 4/ FS/042012/, 2/FS/042012, 3/FS/042012, and 10/FS/2012; 1 paratype male $12 / \mathrm{FS} / 042012$, Mesuji $\left[4^{\circ} 1^{\prime} \mathrm{S}, 105^{\circ} 31^{\prime} \mathrm{E}\right]$, Lampung Province (North), Sumatra, Indonesia, col. Schneider, 


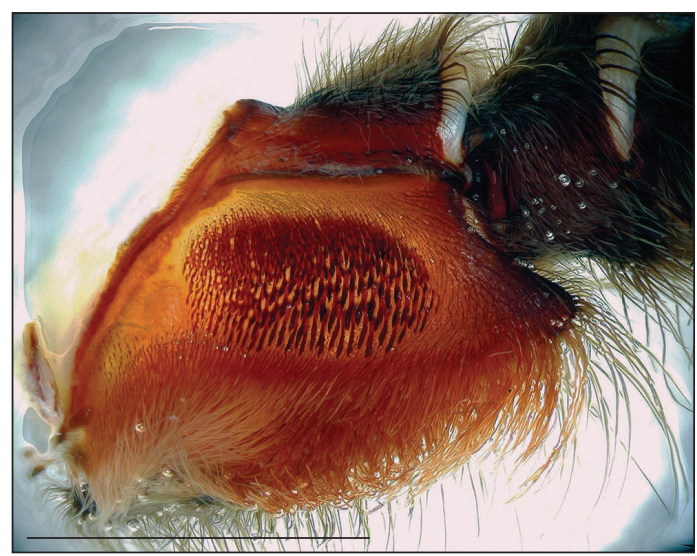

$(27)$

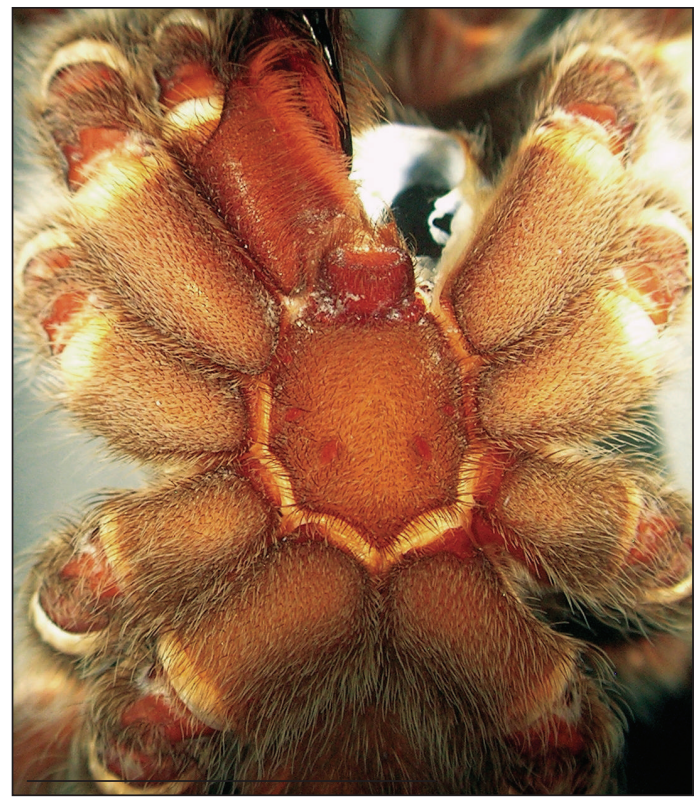

(29)

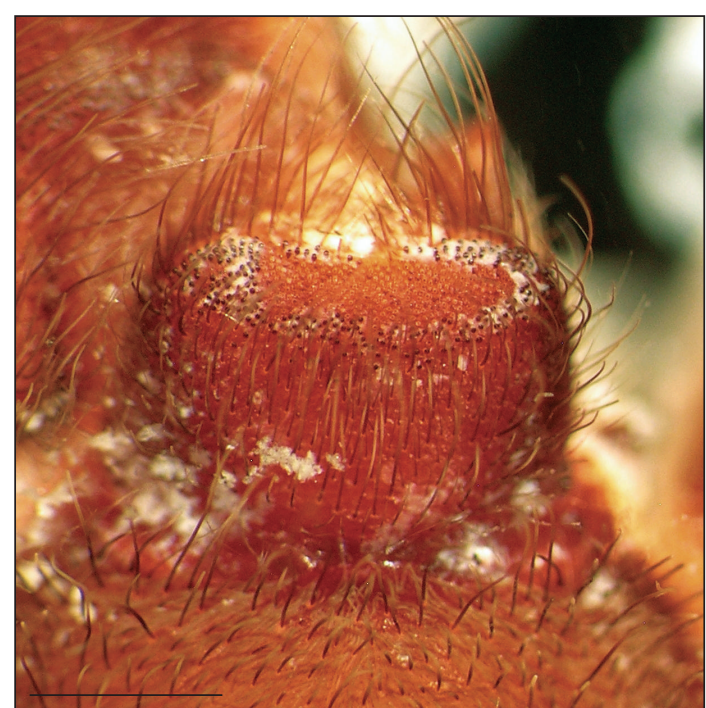

(28)

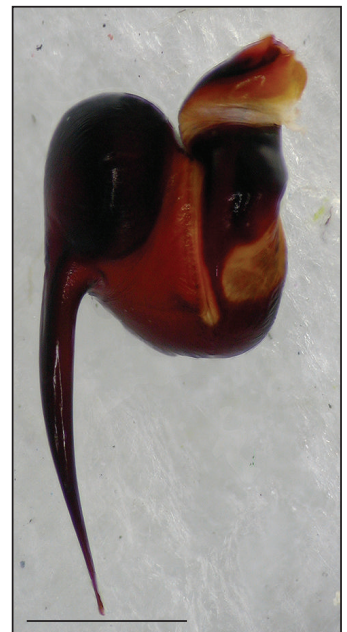

(30)

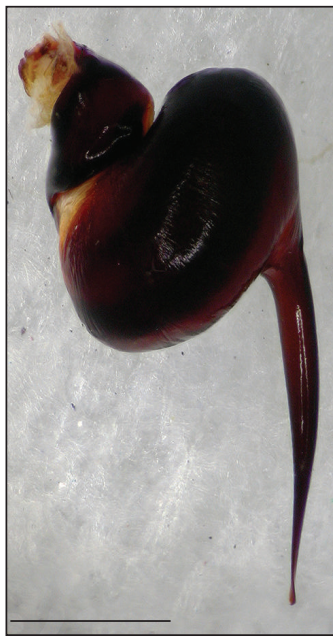

$(31)$

Figure 7: Lyrognathus giannisposatoi sp. nov., paratype males. (27) Maxilla, prolateral view. (28) Labium, ventral view. (29) Sternum, labium, maxilla, and coxae, ventral view. (30) Right embolus, retrolateral view (SMF). (31) Right embolus, prolateral view (SMF). Scale bar $=5 \mathrm{~mm}$ for (27); $2 \mathrm{~mm}$ for (28), (30), and (31); $10 \mathrm{~mm}$ for (29). Photos: (28), (29), Nunn; (27), (30), and (31), Wirth.

April 2012, SMF-examined; 2 paratype females, Mesuji $\left[4^{\circ} 1^{\prime} \mathrm{S}, 105^{\circ} 31^{\prime} \mathrm{E}\right]$, Lampung Province (North), Sumatra, Indonesia, col. Schneider, April 2012, NHM-examined.

Etymology. A patronym in honor of Mr. Gianni Sposato who has provided valuable selenocosmia material, data and assistance to the authors over the last 8 years.

Diagnosis. It differs from all other Lyrognathus species in the much more hirsute border of the carapace, and appears closest related to L. lessunda, but it differs from that species in the more robust build and much larger overall size, longer leg IV $c f$. leg I in both males and females, notably thicker leg IV $c f$. leg I in mature males (legs IV and I are almost equal in L. lessunda), the larger size of the medial pair of sternal sigillae (2/3 size of PSS in L. giannisposatoi sp. nov., 1/2 size of PSS in L. lessunda), ca. twice the number of spiniform setae above the prolateral maxillary suture in females, longer bacilli on lowest row of maxillary lyra in males (bacilli much shorter in L. lessunda), and the morphology and position of patch of the intercheliceral pegs (apically pointed, rough surfaced, and much more robust in L. giannisposatoi sp. nov., blunt tipped, smooth surfaced and more elongated in L. lessunda; patch also extends dorsally into the typical cheliceral setae in $L$. giannisposatoi sp. nov., patch does not extend as far dorsally in L. lessunda). It differs from both $L$. crotalus and $L$. saltator in having intercheliceral pegs (not spines) and retrolateral basomedial cheliceral spines. It differs from $L$. robustus in the undivided scopula for the full length of all metatarsi, third claw absent on tarsi IV, and swollen distal lateral lobes of the spermathecae. It differs from L. fuscus and L. achilles in the more robust build, general leg morphometry, distal cream/white leg segment bands indistinct in females, darker carapace of the male, undivided scopula on tarsi IV in females 


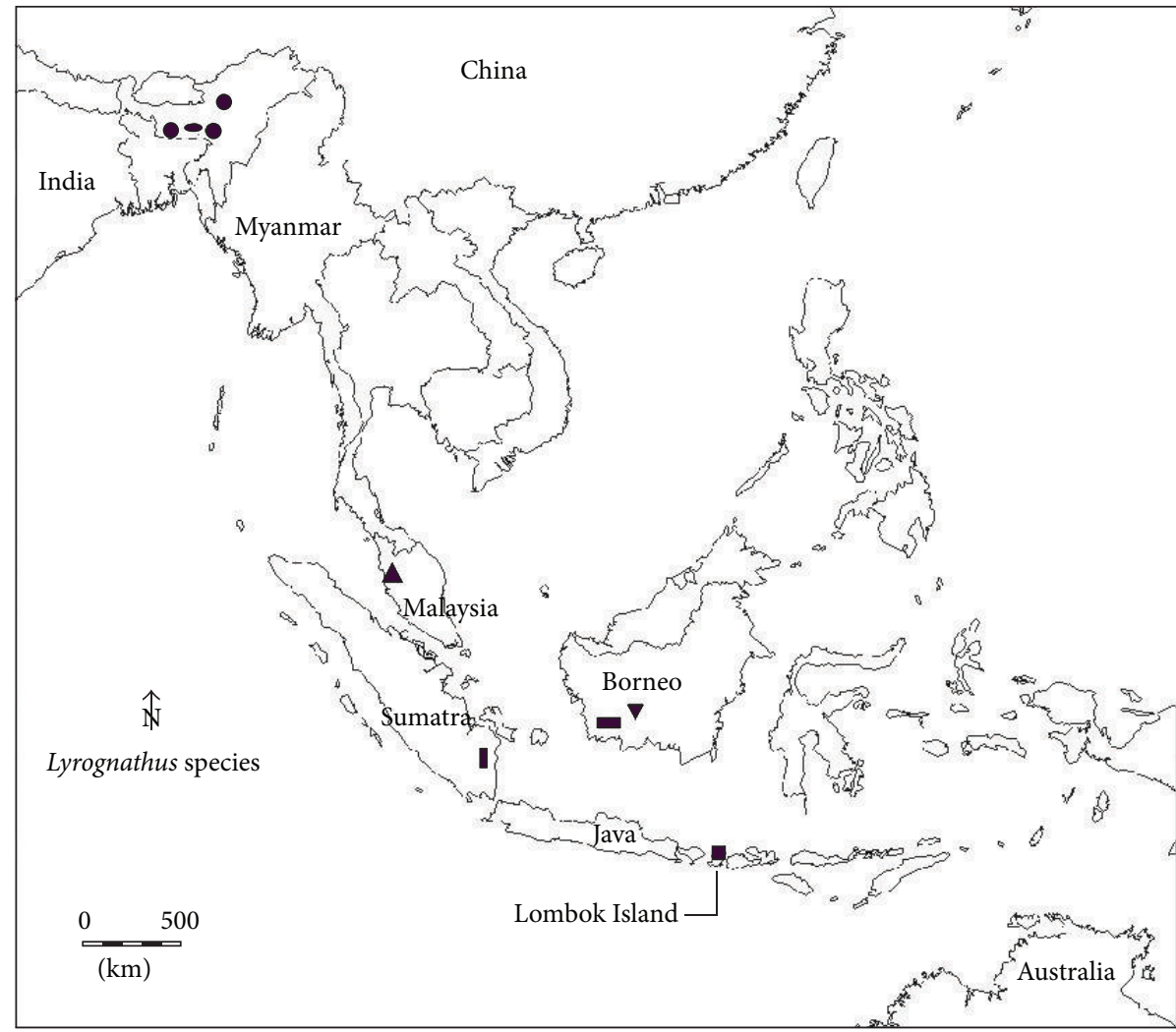

L. achilles
L. crotalus
L. fuscus
L. giannisposatoi sp.nov.

- L. lessunda
A L. robustus
- L. saltator

(32)

FIgURE 8: Distribution of all Lyrognathus species (following West and Nunn 2010, with inclusion of L. giannisposatoi sp. nov.).

(weakly divided by 4-5 setae distally in both L. achilles and L. fuscus), and parted scopula on tar IV lacking any dividing setae in males (4-5 setae distally dividing tar IV scopula in both L. achilles and L. fuscus males).

Description. Female holotype QM S95160 with body length: 44.58. Color (in life, Figure 1): Carapace dark brown, abdomen black, anterior legs I \& II dark brown, anterior legs III \& IV with all femora black, and with indistinct (greatly obscured by setae) cream bands on all leg segments distally. Dorsal coxae, trochantera palest of all. Ventrally black on sternum, coxae, with legs and abdomen as same as seen dorsally.

Carapace (Figure 2): length 19.98, width 14.48 (width across anterior edge 10.6). Fovea 3.39 wide, procurved, deep, smaller in width than OT. The Distance from anterior carapace to fovea is 14.38 . Carapace with 4 discernible hair types ( $\mathrm{C} 1$ to $\mathrm{C} 4)$ : type $\mathrm{C} 1$, long, needle-form pallids bordering carapace entirely (darker basally), setae very dense in number: type C2, long and curling blunt tipped, basally dark grading to distally pallid, and cover entire carapace evenly, these setae grade to become entirely black toward the anterior edge of the carapace: type C3, short, thin wavy pallids, form basis of carapace mat: type $\mathrm{C} 4$ emerge from what resemble bothrial collars, long, distally spiniform, pallid and lie in uniform arrangement of $(>2)$ along anterior edge of each radial groove, $(>6)$ along anterior edge of each thoracic groove, $(>7)$ along anterior edge of each sulcal groove, $(>12)$ along anterior edge of each caput groove, and line of $>5$ along medial caput ridge (between OT and fovea). $>4$ more located behind each side of OT, nearest median caput row.

Eyes (Figure 2(3)): ocular tubercle; length 2.35, width 3.69. OT highest posteriorly behind AME, sloping gradually anteriorly. Anterior row transverse, posterior row recurved. Eyes in lengths/widths: AME: 0.49/0.52, ALE: 0.75/0.35, PLE: 0.46/0.41, PME: 0.51/0.42. Interocular distances: AMEAME: 0.45, AME-ALE: 0.35, AME-PME: 0.2, ALE-ALE: 0.54, ALE-PME: 0.42, PME-PME: 1.51, PME-PLE: 0.19, PLEPLE: 2.45, and ALE-PLE: 0.35. OT hairs: >15 (C2) directly posterior to AME's, 4-5 between PME, and center of OT (directly behind each AME). 20 (C2) along median anterior OT surface. OT entirely covered in small, weak, and pallid setae (C3), directionally pointing to center of OT, posteriorly and anteriorly. Lateral small pallids are very sparse with no uniform direction/random pointing.

Chelicerae (left, paratype female QM S95162, Figures 2(4)-2(8)): length 9.76, width at base of each 


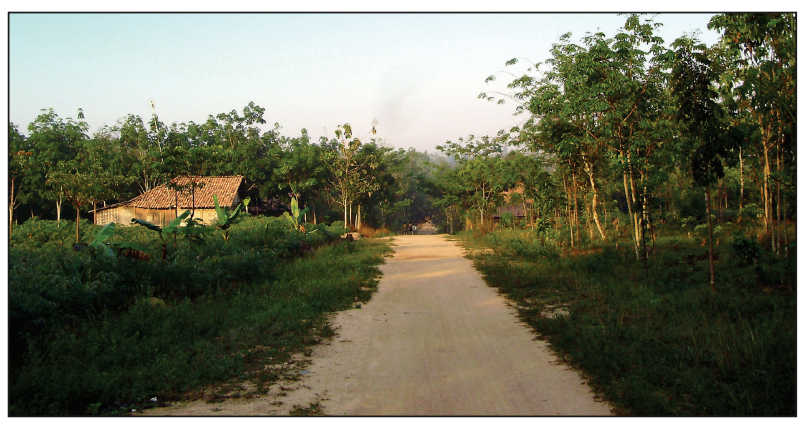

(33)

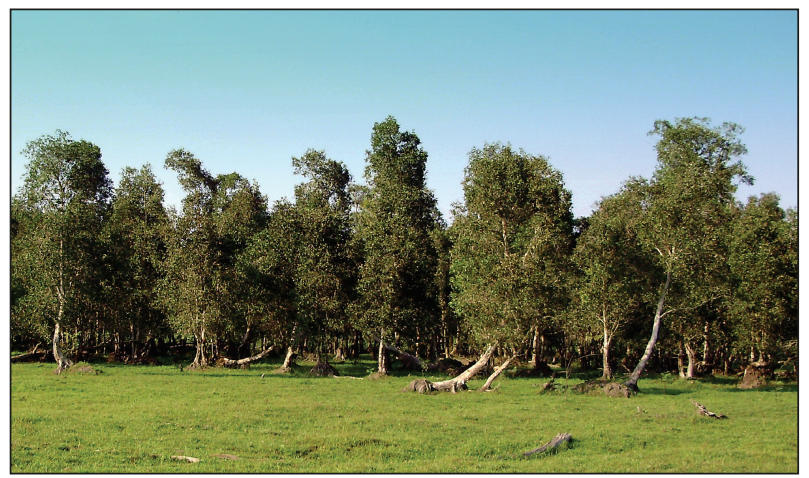

(34)

Figure 9: (33) Human development throughout Mesuji, North Lampung Province, Sumatra (34). Riparian flood plains along the Mesuji River, Sumatra. Photos: Mukhtar.

lobe 4.12 (at bases widest point, dorsally), height: 7.3. Ectal lyrate region a series of strikers $(>78)$ in 6 horizontal rows (Figures 2(4) and 2(7)). Strongest and longest strikers on lowest rows. Each striker is very stout, blade, or scimitar shaped, with long filiform ends (Figures 2(4) and 2(7)). Cheliceral teeth, 13, >56 basomesal teeth. Intercheliceral pegs ( $>11$ larger, $>29$ smaller) in tight cluster on basodorsal surface, very stout, $1 / 3$ as wide as long, distally pointed, rough surfaced, merging with typical cheliceral setae dorsally (Figures 2(5) and 2(6)). On retrolateral cheliceral surface, basomedially, with small cluster of short but strong spiniform setae (>3) and 5 spines (one is broken, but the base is readily visible) pointing distad (Figure 2(8)). Surrounding these spines, notable patch of fine setae, pallid, and of medium length blends into typical thicker pallid retrolateral cheliceral setae. Setae filiform seems to emerge from hemispherical bases.

Maxillae (paratype female QMS95162, Figures 3(9) and $3(10)$ : prolaterally planoconvex, anterior lobe well pronounced, many cuspules $(>250)$ on inner basoventral surface. Lyra (Figures 3(9) and 3(10)): bacilliform rods (>185) form a dense, ovoid patch on prolateral maxillary surface (3.5 long, 2.1 high), lowest row with up to 11 bacillae, longest rods medially in lowest row. Rods distally paddle shaped (paddles up to 0.35 long, paddles lack proximal gradation into shaft) with short to medium length shafts (total rod length including paddles 0.63 ), largest rods with no distal blades. At widest point, lyrate patch 13 rows deep with smallest rods dorsally.
Posterior end of patch truncate but rounded, anterior end rounded. Immediately above maxillary suture $>23$ elongated spines on anterior margin, rows disordered.

Labium (Figure 3(11)): length 2.25, width 3.41. Many small cuspules $(>560)$ along anterior 1/4 surface. Labium with 2 discernible hair types (L1, L2); type L1: long, reasonably dark spiniform, curving distally toward anterior, most concentrated along lateral borders. Setae clearly longest along anterior edge (>35); type L2: 1/2 length of L1, interspersed with L1 but darker, more needle-form.

Sternum (Figure 3(12)): length 9.25, width 7.61, saddleform; with 5 discernible hair types (S1 to S5): type S1, longest, thick, darker basally, becoming pallid distally, entirely over surface, sparse: type S2, elongate spiniforms, dark basally, distally pallid, on margins, most concentrated posteriorly: type S3 absent: type S4, short, thin pallids, form basis of mat: type S5 absent. Posteriorly between left and right coxae IV, border highly acuminate, lateral points slightly acuminate. Sigilla (Figure 3(12)): 3 pairs (not including labiosternal sigilla), posterior, large, right: length 1.21 , width 0.61 , left with length 1.32, width 0.64. Ovular, 2.66 apart, 1.22 to 1.34 from margin. Median pair, 2/3 size of posterior, similar shape, and almost bordering sternal margin. Anterior pair obscured, small, and border margin. Labiosternal sigilla largest, 1.6 times size of PSS with no discernable division between sigilla.

Legs: formula (length); IV, I, II, III: (width); IV, III, I, II. Leg RF 85.53. Leg lengths (fem., pat., tib., met., tar., total): palp: $9.64,6.0,6.47,0.00,6.25,28.36$. I: 13.17, 8.94, 10.22, 9.02, 5.28, 46.63. II: $11.41,7.56,7.58,7.59,5.06,39.2$. III: $10.28,6.96$, 6.22, 8.76, 5.04, 37.26. IV: 14.91, 8.06, 11.96, 14.22, 5.37, 54.52. Leg widths (fem., pat., tib., met., tar., total.): palp: 2.52, 2.86, $2.9,0.00,2.87,11.15$. I: $3.47,3.44,3.42,2.94,2.56,15.83$. II: 3.62, 3.28, 3.07, 2.39, 2.38, 14.74. III: 4.39, 3.69, 3.69, 2.94, 2.26, 16.97. IV: 4.53, 3.78, 4.58, 3.61, 2.8, 19.3. Tib. IV with strong retrolateral villous setal fringe, weakest proximally, grading to thickest distally (Figure 3(13)).

Scopula: met. and tar. I-IV undivided (Figure 4(14), SMF paratype). Met. I-IV, for full length.

Coxae: some small black thorns prolatero-dorsally, no thorns retrolaterally on I-IV. Coxae easily seen dorsally. Cox. I longest, ca. 1.3 times length of II. IV widest, as long as III, basally rectangular with rounded corners. Coxae with small ventral thorns prolaterally on I-IV. I-III ventrally with many long thick blunt setae proximally, pallid. No short black setae. IV with mixture of long thick blunt setae entirely, pallid intermixed with shorter thin pallid setae. Ventral surface of coxae I-IV gently sloping anteriorly. Retrolateral setation: IIII with median narrow light brush, IV entirely covered in short thin pallid setae. I-IV retrolaterally lack ventral ledge. Ventral measurements for coxae: palp length 8.71, width 4.29; I-9.52, 4.34; II-6.42, 4.15; III-6.12, 4.02; IV-8.09, 5.13. Trochantera: palp length 2.48 , width 2.9 ; I-3.9, 3.98; II3.22, 3.65; III-3.86, 34.19; IV-3.83, 4.42.

Trichobothria: on all tarsi basal filiform field slightly wider than clavate field, merges evenly. Clavates on tar. I in distal 1/2 (very dark), long filiforms only in basal 2/3, shorter filiforms intermixed with clavates distally. Clavate extent on tar. II-IV $c f$. I, in distal 1/2. Shorter filiforms for length. Short epitrichobothrial field on I shorter than clavates, increasing in 
length proximally. Tarsal organ evident on legs II-IV under stereo microscope (up to x64), coniform without noticeable ridges. On tar. I, entire field 4.22 long and 1.3 wide distally, to 1.65 wide proximally. On tar. IV, field 4.55 long and 0.86 wide distally, increasing to 1.93 proximally. Metatarsi: trichobothrial field not evident laterally or proximally in any form. Tibia: on tib. I prolaterally and proximally, short, possibly clavate trichobothria noted ( $>8$ per $0.25 \mathrm{~mm}$ squared) in Lshaped patch 0.25 long, 1.25 wide, clearly pallid: $>6$ filiforms in semicircular pattern proximally to rest of patch. On tib. IV prolaterally and proximally, short dark clavates $(>7$ per $0.25 \mathrm{~mm}$ squared) in patch 1.66 long, 0.22 wide distinct: $>7$ filiforms in semicircular pattern proximally to rest of patch.

Spines: met. I with $1 \mathrm{DV}$, met. II with $1 \mathrm{DV}, 1 \mathrm{DPV}, 1 \mathrm{DRV}$, met. III with 1/2 DV, 1DPV, 1 DRV, 1 DD, 1 DPL and met. IV with 1/2 DV, 1DPV, 1 DRV, 1 DD, 1 DPD.

Claws: unarmed paired claws on all legs. Reduced third claw absent on leg IV.

Abdomen (Figure 4(15)): length 19.3, width 14.08. Ovular, elongated, yellow brown (in alcohol); with 4 discernible hair types (A1 to A4): Dorsally with 3 hair types: type A1 long, dark blunt tipped, uniform: type A2 mid-length, also dark, but distally spiniform, unlike type A1: type A3 form dense mat, midlength, uniformly dark, needleform (some stand erect, some posteriorly, but share similar morphology). Longest hairs (type A1) more concentrated posteriorly toward spinnerets, point distad, but toward proximal region, hairs stand erect, medially curved (toward posterior). Ventral hair types almost same as dorsal, although type $\mathrm{A} 2$ and $\mathrm{A} 3$ more dense entirely. Type A4 hair in very dense patch, trapezoid, posterior of pedicel between median regions of cox. IV. Hairs of medium length, wavy and pallid. Between anterior pair of book lungs, setal mat uniform with rest of venter (Figure 4(16)).

Genitalia (Figure 4(17)): epigastric fold 7.41 wide. Spermathecae paired but not fused, separated by 0.95 (width including spermathecae 2.08), bilobular apically, each lobe with strong apical rounded appendages, lateral/outer lobes distally swollen, ovular: lateral lobe distal widths 0.55 (left)0.56 (right): medial lobe distal widths 0.36 (left) -0.33 (right), heavily sclerotized entirely. Lobes apically swollen, lateral lobes (including shaft length) at 2/3-4/5 length to medials. Epigastric fold extends to $c a .2 / 3$ length of spermathecal lobes. Lobes among paratypes show some variation (Figures 4(17)$4(20))$.

Spinnerets: PMS: length 1.79, width (medially) 0.73. PLS: section lengths; basal 2.71, medial 1.35, apical 3.34. PLS section widths (medially); basal 1.81, medial 1.11, apical 1.09. Spinnerets with 2 discernible hair types (SP1, SP2): SP1 very short and distally blunt pallid, covers both pairs ventrally, second form (SP2), very similar but up to three times longer, dorsally on all segments.

Male paratype QMS95161 (SMF male type where mentioned, as in female except) with body length: 35.75 .

Color (in life, Figure 5): Carapace and legs dark grey (except femora). Coxae and trochantera palest dorsally with a subtle pinkish color. Tarsi I \& II with rufus longitudinal band dorsally. Abdomen and all femora black. All leg segments display strong distal white lateral banding.
Carapace (Figure 6(22)): length 14.89, and width 11.37 (width across anterior edge 8.66). Fovea 2.68 wide, procurved, deep, narrower than OT. Distance from anterior carapace to fovea, 11.01. Carapace hair types as in female. Eyes (Figure 6(23)): ocular tubercle; length 2.11, width 3.49.

Chelicerae (right, Figures 6(24)-6(26)): length 7.65, width at base of each lobe 3.45 (at bases widest point, dorsally). Ectal lyrate region a series of strikers $(>89)$ in 6 horizontal rows. Cheliceral teeth, $12,>25$ basomesal teeth. Intercheliceral pegs ( $>12$ larger, $>23$ smaller) in tight cluster on basodorsal surface, pegs less elongate than in females (Figure 6(26)).

Maxillae. Lyra (Figure 7(27), SMF paratype): large number of bacilliform rods (>185) form dense, ovoid patch on prolateral surface (3.01 long, 1.45 high), with lowest row composing of $>17$ bacillae, longest rods in center of lowest row. Rods distally paddle shaped (paddles to 0.26 long), total length including paddles to 0.62 , largest with no distal blades. At widest point, lyrate patch 13 rows deep, smallest rods dorsally. Posterior end of patch truncate but rounded, anterior end widely rounded. Immediately above suture $>12$ spiniform setae on anterior margin in disordered rows. Labium (Figure 7(28)): length 1.73, width 2.39. Many small cuspules $(>420)$ along anterior $1 / 4$ surface.

Sternum (Figure 7(29)): length 6.34, width 5.53, saddleform. Sigilla: 3 pairs, posterior large; right with length 0.89 , width 0.43 , left with length 0.88 , width 0.41 . Ovular, 1.67 apart, 1.12-1.18 from margin. Median pair 1/2 size of posterior, similar shape, $0.5-0.8$ of their length from margin. Anterior pair obscured by setae, $2 / 3$ size of median pair and bordering sternum. Labio-sternal sigilla largest, 1.6 times size of PSS.

Legs: formula (length); IV, I, II, III: (width); IV, III, I, II. Leg RF 94.33. Leg lengths (fem., pat., tib., met., tar., total): palp: $8.86,5.68,7.37,0.00,3.2$, 25.11. I: $13.45,7.63,11.42,10.49$, 5.63, 48.62. II: $11.06,6.99,8.28,9.21,5.25,40.79$. III: 9.87, 5.57, 8.65, 9.04, 4.79, 37.92. IV: $14.14,6.95,11.31,14.03,5.11,51.54$. Leg widths (fem., pat., tib., met., tar., total.): palp: 2.22, 2.13, 2.21, $0.00,2.15,8.71$. I: $3.36,2.59,2.63,2.01,1.78,12.37$. II: $3.0,2.76$, $2.21,1.73,1.59,11.29$. III: $3.85,3.01,2.66,2.03,1.83,13.38$. IV: $3.69,2.92,2.76,2.41,1.82,13.6$. Tib. IV with retrolateral villous setal fringe, proximally to distally uniform, not as elongate or dense as in females. Ventral measurements for coxae: palplength 7.01, width 3.2; I-6.63, 3.56; II-5.6, 3.12; III-4.17, 3.51; IV-6, 3.76. Trochantera: palp-length 2.97, width 2.43; I-3.38, 3.32; II-3.15, 3.12; III-2.92, 3.39; IV-3.09, 3.95 .

Scopula: Tar III and IV parted, but not by dividing line of setae.

Abdomen: length 14.55, width 8.21.

Genitalia: Palp (Figures 7(30) and 7(31), SMF paratype): tibia mildly incrassate, tapering distally. Cymbium bipartite, tegulum large. Lanceolate embolus slightly tapering distally, very little flaring, proximally emerges anterior to tegulum. Relative length of palpal tibia about three times length of embolus. Longitudinal keel present, but reduced, not distinct (embolus not terete), along entire length of embolus, twisted through $90^{\circ}$ prolaterally distally (Figure $7(31)$ ).

Spinnerets: PMS: length 1.66, width (medially) 0.93. PLS: section lengths; basal 1.79, medial 1.34, apical 2.75. PLS section widths (medially); basal 1.21, medial 0.82, apical 0.65. 
Distribution and Natural History. (Figures 8-9(34)): Known only from the type locality, Mesuji, Lampung Province (north), Sumatra, Indonesia (Figure 8). Little is known; however, L. giannisposatoi sp. nov. is a fossorial spider that lives at very low elevation, but on higher rises of land, just above the riparian flood plains of the Mesuji River. This region is heavily disrupted by human development and agriculture (Figure 9(33)); however, specimens are reportedly found in uncleared patches of gallery forest (Figure 9(34)). Males are known to mature and breed in July while mature females produce egg sacs in the same month. The number of eggs in the egg sac ranged from 200-300. From egg sacs kept and artificially incubated in captivity, the emergence of young spiderlings occurs from late October to early November. (Schneider, Verdez, Jörg Broghammer, pers. comm.).

Biogeographical History. As discussed by West et al. [6, page 36], East and South East Asian flora and fauna show complex patterns of divergence that are closely allied to the geological history of the region [18]. West et al. [6, page 36] hypothesized that Selenocosmiinae had begun divergence prior to the breakup of Gondwana although it appears Lyrognathus had not diverged until sometime after the land masses that currently form the Malay Archipelago had reassembled $\sim 220-80 \mathrm{Ma}$ [19]. Due to the disjunct population of 2 species in North East India, West et al. [6, page 38] suggested that Lyrognathus most likely diverged sometime between the eventual accretion of the Malay Peninsula (including the rifting of Sibumasu, part of which became Sumatra) ( 220$80 \mathrm{Ma}$ ) and the collision of the Indian landmass with both Sumatra and the Malay Peninsular $(\sim 40 \mathrm{Ma})$, before India finally accreted with Lower Eurasia ( $35 \mathrm{Ma})$, following Ali and Aitchison [20]. West et al. [6] suggested that such a hypothetical account for the entire range of Lyrognathus including the disjunct NE Indian populations, and furthermore it is, therefore, of little surprise that Lyrognathus still exists on the island of Sumatra (this paper).

\section{Abbreviations}

ALE: Anterior lateral eyes

AME: Anterior median eyes

cox.: Coxa

D: Dorsal

DD: Distodorsal

DL: Distolateral

DPD: Distal prodorsal

DPL: Distal prolateral

DPV: Distal proventral

DRD: Distal retrodorsal

DRV: Distal retroventral

DV: Distoventral

fem.: Femur

Ma: Millions of years before the presen

met.: Metatarsus

OT: Ocular tubercle

P: Prolateral

pat.: Patella

PLE: Posterior lateral eyes
PLS: Posterior lateral spinnerets

PME: Posterior median eyes

PMS: Posterior median spinnerets

PSS: Posterior sternal sigilla

R: Retrolateral

tar.: Tarsus

tib.: Tibia

tro.: Trochanter

V: Ventral.

\section{Acknowledgments}

Thanks to Mr. Frank Schneider for bringing this species to our attention and for supplying both live and preserved materials and to Martin Gamache for relaying specimens to the authors. Thanks to Mr. Volker von Wirth for his assistance with critical comments on the paper, for providing additional type material, and for images hastily provided upon request. A grateful thank you to Mr. Heinrich J. Buys for assisting with image editing at the last minute. Thanks to Mr. Frank Schneider, Mr. Jean-Michel Verdez, and Mr. Jörg Broghammer for assistance with natural history notes. The authors are also grateful to Mr. Syamsurrizal Mukhtar for habitat images and to Mr. JeanMichel Verdez for providing an image of a live mature male. Images and illustrations of type material were kindly supplied by Dr Robert Raven, Mr. Andrew Smith, and Mr. Volker von Wirth. Dr Owen Seeman and Ms Wendy Hebron (QM) are thanked for their tireless efforts transporting and preparing type material. Dr. H. Don Cameron and Dr G. B. Edwards kindly checked the Latin names.

\section{References}

[1] R. I. Pocock, "On a new and natural grouping of some of the Oriental genera of Mygalomorphae, with descriptions of new genera and species," The Annals and Magazine of Natural History, vol. 15, no. 6, pp. 165-184, 1895.

[2] R. I. Pocock, “The fauna of British India, including Ceylon and Burma," in Arachnida, p. 279, Taylor and Francis, London, UK, 1900.

[3] A. M. Smith, The Tarantula: Classification and Identification Guide, Fitzgerald Publishing, London, UK, 1986.

[4] R. C. West, "A new theraphosid spider from the Cameron Highlands, Malaysia," Memoirs of the Queensland Museum, vol. 30, pp. 615-619, 1991.

[5] R. C. West and S. C. Nunn, "A taxonomic revision of the tarantula spider genus Lyrognathus Pocock 1895 (Araneae, Theraphosidae), with notes on the Selenocosmiinae," Zootaxa, no. 2362, pp. 1-43, 2010.

[6] R. C. West, S. C. Nunn, and S. Hogg, "A new tarantula genus, Psednocnemis, from West Malaysia (Araneae, Theraphosidae), with cladistic analyses and biogeography of Selenocosmiinae Simon 1889," Zootaxa, vol. 3299, pp. 1-43, 2012.

[7] A. M. Smith, "Lyrognathus robustus, a new species of theraphosid spider from Malaysia," British Tarantula Society Journal, vol. 4, no. 2, pp. 15-19, 1988.

[8] R. J. Raven, "A new tarantula species from northern Australia (Araneae, Theraphosidae)," Zootaxa, no. 1004, pp. 15-28, 2005. 
[9] V. von Wirth and B. F. Striffler, "Neue Erkenntnisse zur Vogelspinnen-Unterfamilie Ornithoctoninae, mit Beschreibung von Ornithoctonus aureotibialis sp. n. und Haplopelma longipes sp. n. (Araneae, Theraphosidae)," Arthropoda, vol. 13, no. 2, pp. 2-27, 2005.

[10] E. Simon, "Histoire naturelle des araignées," Paris, vol. 2, pp. 669-1080, 1903.

[11] F. H. Gravely, "The evolution and distribution on Indian spiders belonging to the sub-family Aviculariinae," Journal and Proceedings of the Asiatic Society of Bengal, vol. 10, pp. 411-420, 1915.

[12] F. H. Gravely, "Notes on Indian mygalomorph spiders-I," Records of the Indian Museum, vol. 11, pp. 257-287, 1915.

[13] F. H. Gravely, "Notes on Indian mygalomorph spiders-II," Records of the Indian Museum, vol. 37, pp. 69-84, 1935.

[14] C. F. Roewer, "Katalog der Araneae von 1758 bis 1940," Bremen 1, p. 1040, 1942.

[15] R. J. Raven, “The spider infraorder Mygalomorphae (Araneae): cladistics and systematics," Bulletin of the American Museum of Natural History, vol. 182, pp. 1-180, 1985.

[16] A. M. Smith, The Tarantula: Classification and Identification Guide, Fitzgerald Publishing, London, UK, 2nd edition, 1987.

[17] N. I. Platnick, "The world spider catalog, version 9.5. American Museum of Natural History," 2013, http://research.amnh.org/ entomology/spiders/catalog/index.html.

[18] I. Sanmartín and F. Ronquist, "Southern hemisphere biogeography inferred by event-based models: plant versus animal patterns," Systematic Biology, vol. 53, no. 2, pp. 216-243, 2004.

[19] I. Metcalfe, "Palaeozoic and Mesozoic geological evolution of the SE Asian region, multidisci plinary constraints and implications for biogeography," in Biogeography and Geological Evolution of SE Asia, R. Hall and J. D. Holloway, Eds., pp. 25-41, Backhuys Publishers, Amsterdam, The Netherlands, 1998.

[20] J. R. Ali and J. C. Aitchison, "Gondwana to Asia: plate tectonics, paleogeography and the biological connectivity of the Indian sub-continent from the Middle Jurassic through latest Eocene (166-35 Ma)," Earth-Science Reviews, vol. 88, no. 3-4, pp. 145$166,2008$. 

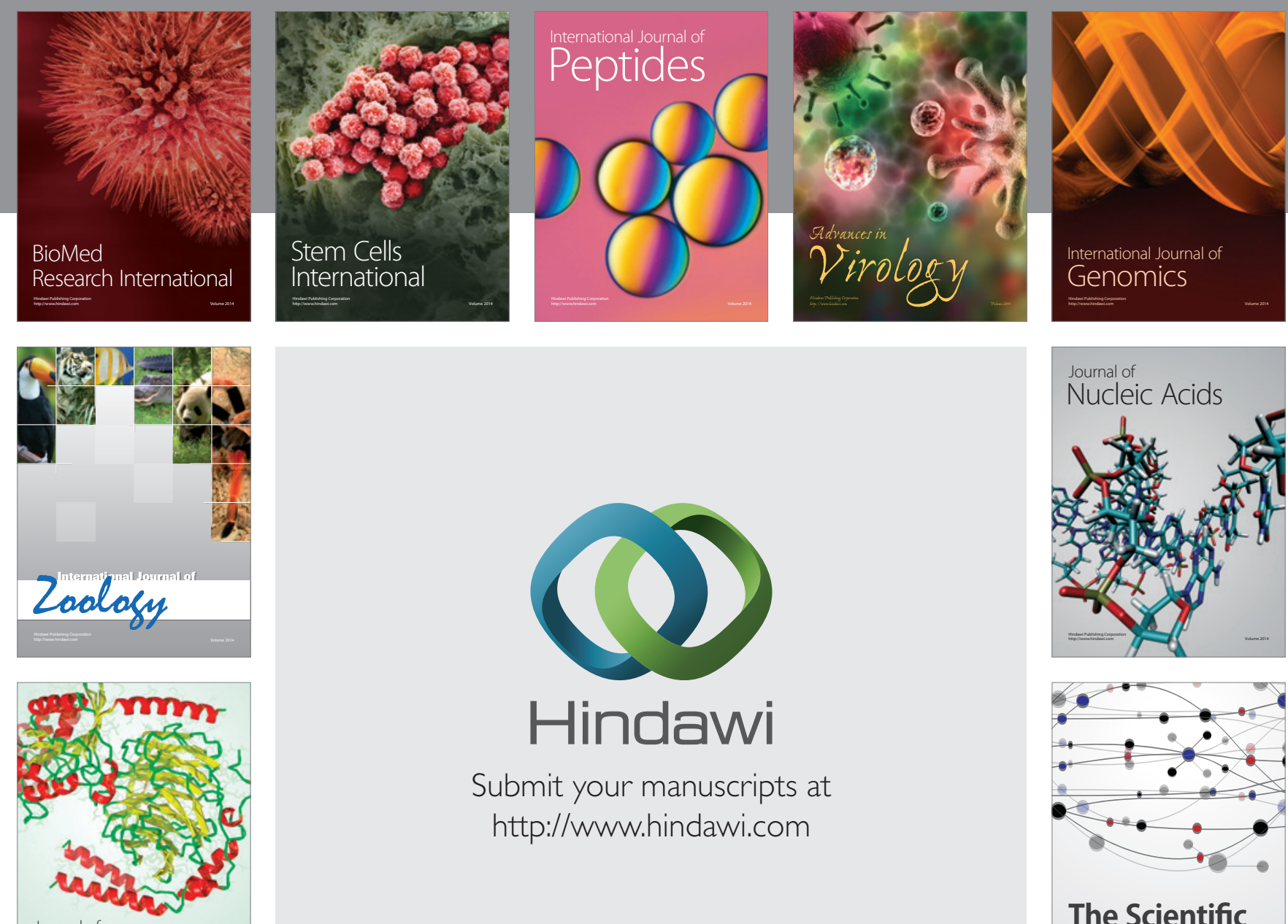

Submit your manuscripts at

http://www.hindawi.com

Journal of
Signal Transduction
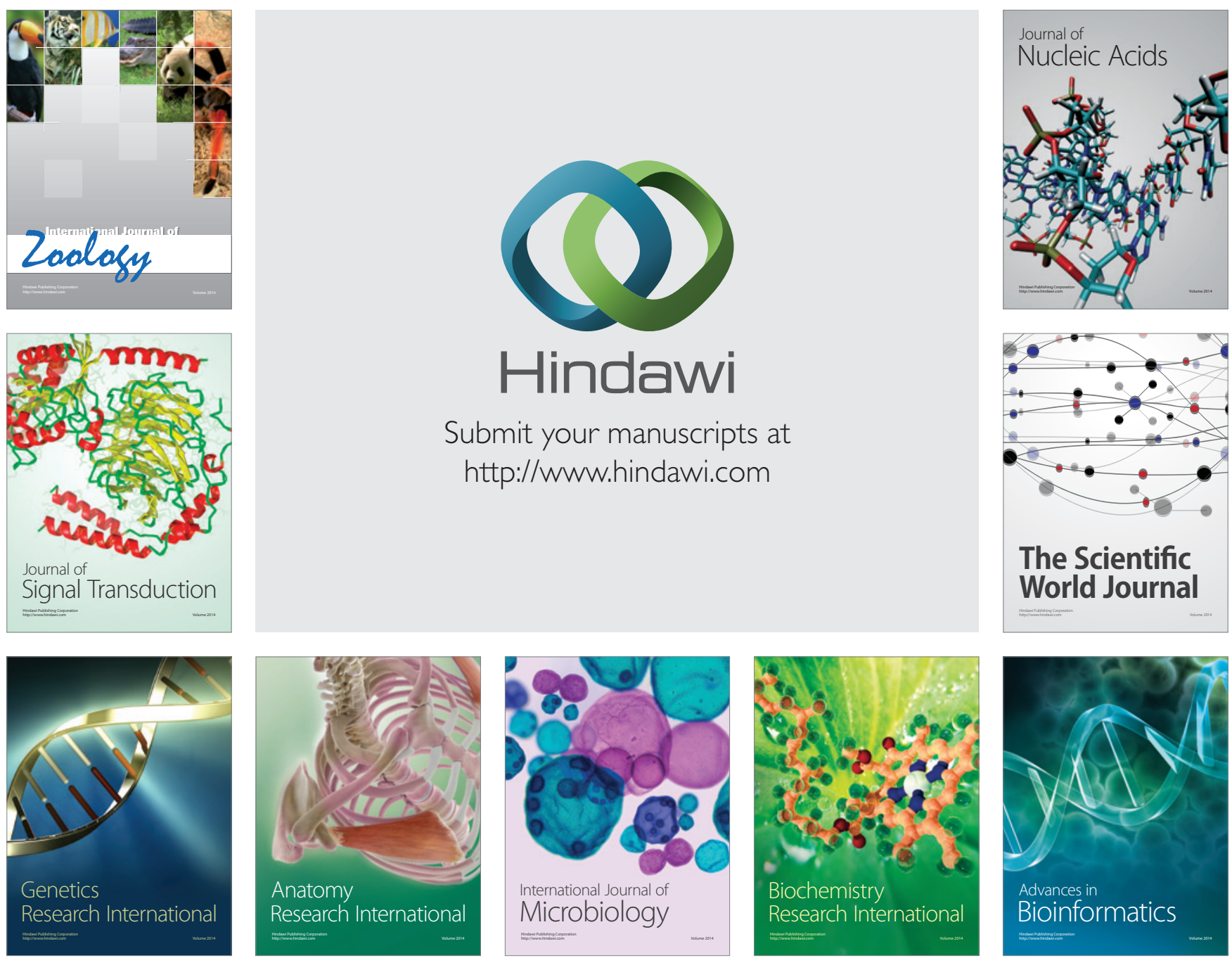

The Scientific World Journal
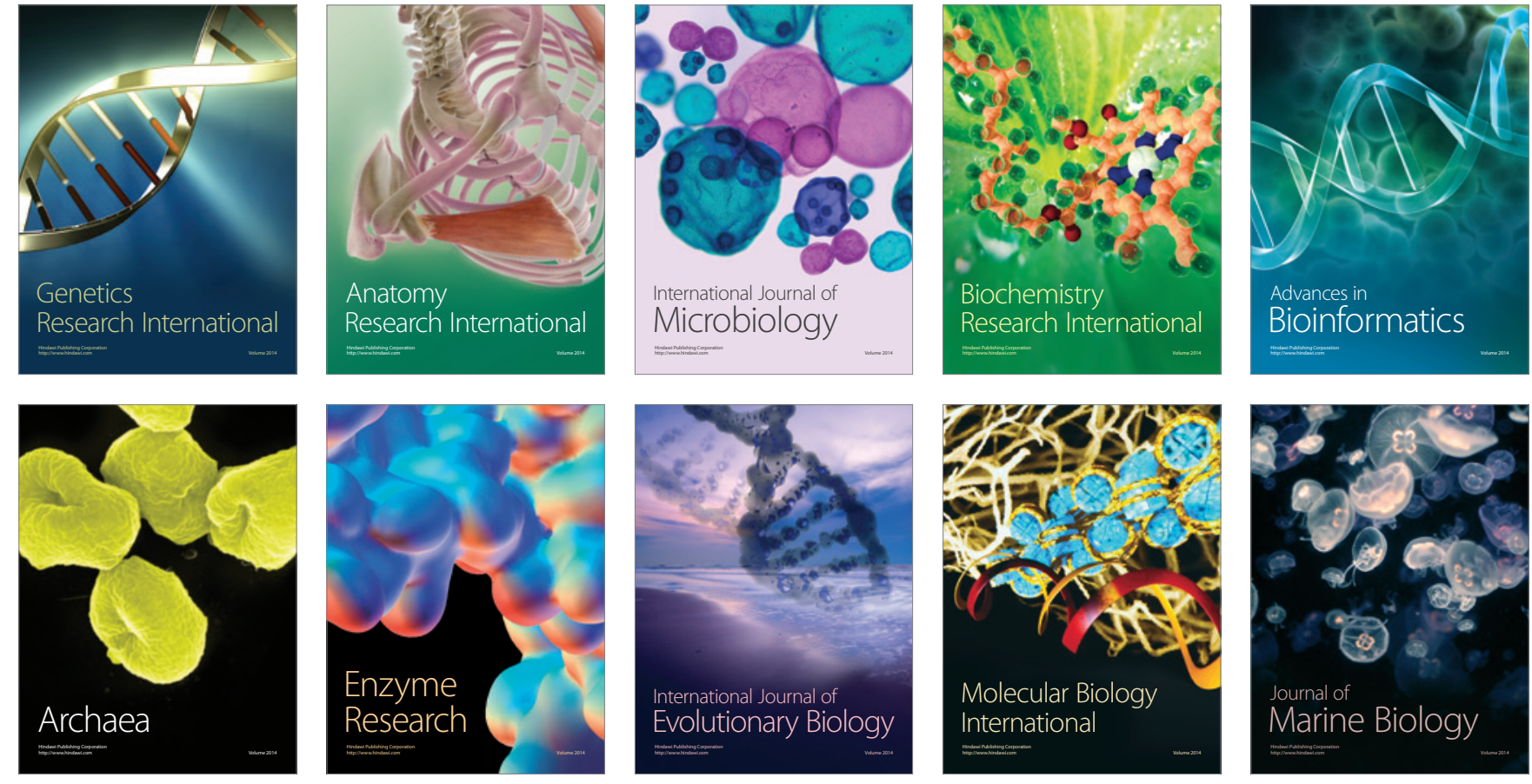